\title{
The Altered Cerebral Homeostasis with Aging in Diabetes Mellitus and Cognitive Decline
}

\author{
Vinod Nikhra* \\ Chief Medical Officer and Consultant, Department of Medicine, India \\ *Corresponding author: Vinod Nikhra, Senior Chief Medical Officer and Consultant, Department of Medicine, Hindu Rao Hospital and NDMC Medical \\ College, New Delhi, India
}

Submission: 眥 February 05, 2018; Published: 漈 April 27, 2018

\begin{abstract}
Overview-Diabetes and Cerebral Metabolism: Diabetes mellitus (DM) per se adversely alters cerebral metabolism, promotes cerebral atrophy and accelerate brain aging, and affects cognitive function. There is a consensus now that the cognitive decline should be listed as one of the major complications of diabetes. The insulin receptors are widely expressed in the brain and insulin as a pleiotropic peptide plays various roles in cerebral metabolism, neuronal growth, neuroplasticity and neuromodulation, and cognitive processes such as reward, motivation, cognition, attention, and memory formation. The insulin signaling mediates various alterations in neuronal integrity and functions in both the patients with type 1 diabetes mellitus (T1DM) and type 2 diabetes mellitus (T2DM).
\end{abstract}

Contributors to Cognitive Decline in DM: There are various factors that contribute to the development of cognitive decline in patients with DM. Adults with diabetes have also been found to have structural changes, including atrophy and leukoariosis. The extremes in glycemia experienced by patients with T1DM and advanced T2DM have an impact on brain, and chronic exposure to recurrent hyperglycemias and hypoglycaemia leads to alterations in brain structure and function. During hyperglycemias in patients with both T1DM and T2DM, there is slowing of cognitive function, increased number of mental subtraction errors, loss of inhibition and focus, impaired speed of information processing, decreased attention, and impaired working memory. Higher glycated haemoglobin values are associated with moderate declines in motor speed and psychomotor efficiency.The hypoglycaemia also affects the cognitive functions adversely. The cortex, basal ganglia, and hippocampus are especially vulnerable to hypoglycaemia, and hypoglycaemia selectively damages neurons with sparing of astrocytes and oligodendrocytes. The impaired hypoglycaemia awareness adds to the cognitive function. Because the brain depends almost exclusively on glucose, recurrent hypoglycaemia may be a threat for cognitive dysfunction and cerebral damage, and the patients with DM are at increased risk for accelerated cognitive decline and dementia.

The Role of Insulin Resistance: There is evidence that insulin resistance (IR), a factor contributing to the onset of T2DM, may play a role in the pathogenesis of $\mathrm{MCI}$ and $\mathrm{AD}$, which are approximately 1.2-to1.7-fold higher in patients with T2DM compared with a control population. On the other hand, T2DM is also more common in patients with AD. The IR has been correlated to increased neuro-inflammation, inflammatory markers and vascular disease. It also causes disruption of the hypothalamic-pituitary adrenal axis and increased cortisol levels which may contribute to cognitive dysfunction. Finally, the IR contributes to cognitive dysfunction by affecting the metabolism of APP and $\beta$-amyloid leading to accumulation of $\beta$-amyloid and promoting the formation of senile plaques.

The Impact of Longstanding DM: With aging in diabetic patients, the intrinsic brain tissue changes, vascular disease and alterations in cellular bioenergetics hamper the brain's ability to cope up with metabolic stress. There occur cerebral structural and functional alterations like, cerebral atrophy and white matter lesions, micro-hemorrhages and lacunar infarcts, and neuronal dysfunction and network alterations. Patients with DM have a 2-to 6-fold increased risk of vascular disease. There occurs thickening of capillary basement membranes in cerebral vasculature, which is the hallmark of diabetic microangiopathy, and leads to decreased cerebral blood flow, which is akin to that encountered in AD. The decrease in cerebral blood flow, coupled with the stimulation of the thromboxane A2 receptor contributes to the inability of cerebral vessels to adequately vasodilate, and increases the likelihood of ischemia. The coexistence of ischemia and hyperglycemias may be particularly detrimental to the brain.

Conclusion-Search for the Solutions: The cognitive decline affects ADL and QOL, it affects life expectancy also. The MCI is a stage before dementia, and when accompanied by DM, its progression to dementia is accelerated. There is preponderance of lifestyle-related diseases, such as adiposity, metabolic syndrome, IR, hypertension and dyslipidemia, in the middle aged, and risk factors for cardiovascular disease accumulate in diabetic patients. This leads to a subclinical inflammatory state which has been related to a higher risk of cognitive decline and dementia, including vascular dementia and late onset AD.

Keywords: Cerebral metabolism; Cognitive decline; Diabetic complications; Insulin resistance; Diabetic vascular disease; Diabetic microangiopathy; Mild cognitive decline (MCI); Alzheimer's disease (AD); Vascular dementia; Metabolic stress; Calorie restriction (CR); Calorie restriction with adequate nutrition (CRAN) 


\section{Overview: Diabetes Mellitus, Aging and Cognitive Dysfunction}

The aging is the accumulation of alterations over time at cellular, tissue and organ levels in an organism. Further, the aging is characterized by alterations in metabolism and homeostasis, and affects carbohydrate homeostasis by altering pancreatic $\beta$ cell function, $\beta$ cell mass, insulin secretion and insulin sensitivity, and predisposes for insulin resistance (IR), impaired glucose tolerance and diabetes. Thus, the aging is an important risk factor for metabolic disorders including obesity, impaired glucose tolerance, and type 2 diabetes mellitus (T2DM). The prevalence of T2DM and its complications increase with age, and predispose to various agerelated diseases such as atherosclerosis, cardiovascular disease (CVD), stroke, Alzheimer disease (AD), Parkinson's disease and cognitive decline.

\section{DM and cognitive decline}

During the recent years, there have been significant advances in our understanding the way diabetes mellitus (DM) adversely alters cerebral metabolism, promotes cerebral atrophy and accelerates brain aging, and affects cognitive dysfunction. The cognitive decline is, thus, a well-established complication of DM is in both the patients with type 1 diabetes mellitus (T1DM) and T2DM, and there is a consensus now that the cognitive decline should be listed as one of the major complications of diabetes, like retinopathy, neuropathy, nephropathy, and cardiovascular disease. With aging, there is an alteration in cellular structure and central nervous system (CNS) physiology, which is influenced by genetic, epigenetic, as well as environmental factors and results in consequential disturbances in synaptic signaling and discrete neural circuits. The insulin as a pleiotropic peptide plays various roles in both cerebral metabolism and cognitive processes in CNS, and the alterations in neuronal integrity and function appear to be mediated by abnormal central insulin signaling.

There have been identified various neurocognitive abnormalities and dementia including Alzheimer's disease (AD), the incidence of latter is about 2-3 times higher in diabetics than in non-diabetics [1]. As documented by epidemiological studies, T2DM can be considered an independent risk factor for dementia [2], and the risk of dementia increases with the duration of disease [3]. The same, though, appears not be true for patients with T1DM as compared with the rest of the population. There was found no evidence of substantial long-term declines in cognitive function in a large group of patients with T1DM who were carefully followed for an average of 18 years, despite relatively high rates of recurrent severe hypoglycaemia [4]. Further, despite relatively high rates of severe hypoglycaemia, cognitive function did not decline over an extended period of time in the youngest cohort of patients with T1DM [5].

The results from certain studies are important to note and correlate. The Action to Control Cardiovascular Risk in DiabetesMemory in Diabetes (ACCORD-MIND) trial, whose aim was intensive control in T2DM patients, observed a decline in cognitive function over time, and effects of intensive glycemia control were not shown [6]. In the Atherosclerosis Risk in Communities (ARIC) study, while an analysis of all subjects including non-diabetics found that glycosylated haemoglobin A1C (HbA1c) level was associated with progression of cognitive impairment in motor speed, an analysis on the diabetic subjects only did not find such an association [7]. Also, the Hisayama study showed a high prevalence of $\mathrm{AD}$ and vascular dementia in subjects in whom glucose intolerance had been observed 15 years previously [8].

\section{Discovery of the link}

The association between abnormal glucose metabolism and neurological disorders was first documented by Willis [9] (16211675), who noted that diabetes often appeared among persons experiencing stressful and sad life events [9]. On lines of the Willis' hypothesis, much later in 1935, Menninger [10] postulated the existence of psychogenic diabetes and coined the term, diabetic personality [10]. Since then, the accumulating evidence from experimental animal and human clinical studies have outlined a bidirectional association between diabetic metabolic disturbances and neuropsychiatric disorders (Figure 1). The diabetics have an increased risk for developing depression [11]. Further, those suffering from depression have a higher risk of developing T2DM by approximately 60 percent [12].

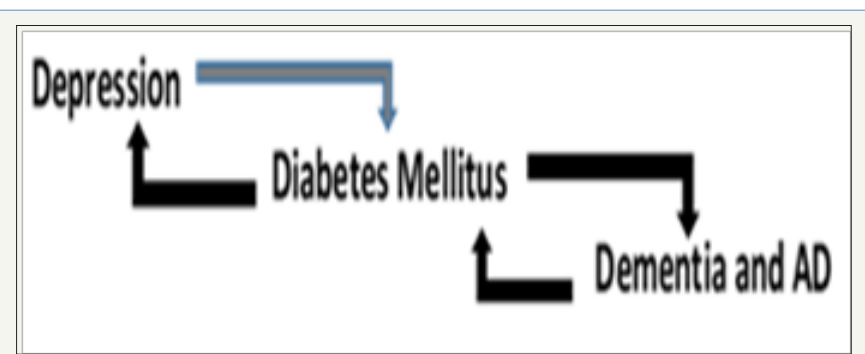

Figure 1: Three Ds: The bi-directional links between diabetes and depression, and dementia.

In DM, apart from alterations in the cerebral metabolism, structure, and functions, there are further challenges to cerebral homeostasis in form of hyperglycemias due to suboptimal treatment and therapy-associated hypoglycaemia. These metabolic challenges have an impact on the brain, which may depend on the age of the individual, their stage of neurological development, period of the illness and whether they have T1DM or T2DM.

The results from various studies indicate that hypoglycaemia in children with T1DM, is consistently associated with a reduction in neurocognitive function. Whereas, Both hypoglycaemia and hyperglycemias have been associated with long-term cognitive decline and dementia in adults T2DM. In addition, in both T1DM and T2DM, the recurrent episodes of treatment-associated hypoglycaemia impair perception and response to subsequent episodes of hypoglycaemia. Whereas, the uncontrolled DM affects adversely the brain metabolism and function and various altered cerebral functional aspects may be indirectly linked to the abnormal cerebral glucose metabolism. Neurotransmitter metabolism, cerebral blood flow, blood-brain barrier and micro vascular 
function are affected to varying degrees by chronic hyperglycemias, in the context of insulin resistance and relative insulin deficiency. Hyperglycemias damage certain cells, including neurons, which are unable to reduce the transport of glucose inside the cell, leading to high intracellular glucose. This has been associated with neuronal dysfunction, cognitive deficits, accelerated cognitive decline, an increased risk of vascular dementia, and AD. As documented, In T2DM, cognitive changes mainly affect learning, memory and information processing speed [13].

\section{The role of astrocytes}

In normal situation, cerebral function is associated with exceptionally high metabolic activity, and requires continuous supply of oxygen and nutrients from the blood stream. The brain energy metabolism is compartmentalized in neurons and astrocytes, and astrocytes glycolysis serves the energetic demands of glutamatergic activity. Apart from scaffold-associated function, astrocytes in brain play various roles. With the development and optimization of non-invasive techniques, such as nuclear magnetic resonance spectroscopy, The understanding about astrocytes metabolism have become clear [14]. The rate of oxidative metabolism in astrocytes is about half of that in neurons, and can increase as much as the rate of neuronal metabolism in response to synaptic stimulation to support neurotransmissionassociated functions, such as restoration of ion gradients caused by action potentials, post-synaptic currents, and transport of glutamate into vesicles. In addition, the glial metabolism provides energy for neurotransmission besides housekeeping tasks, likely fuelling the production and action of modulators of neuronal activity and of synaptic plasticity, supply of antioxidant molecules and neurotrophic factors that are necessary for adequate brain function, and regulation of blood circulation. Moreover, the astrocytes are important source of glycogen that can be used for neurotransmission support and during hypoglycaemic episodes.

\section{The Normal and Altered CNS Metabolism in DM}

\section{The normal brain metabolism}

The brain uses glucose as its primary fuel and the cerebral metabolism requires glucose transport through the blood-brain barrier, glycolytic conversion to pyruvate, metabolism via the tricarboxylic acid cycle and oxidation to carbon dioxide and water to generate adenosine triphosphate (ATP). Further, glucose is stored as glycogen in astrocytes, which is important for tolerance of hypoglycaemia, metabolic response to somatosensory stimulation and cellular metabolism. Normal and pathological conditions (such as nutrients and oxygen, hormones, stress and inflammatory factors) have immediate impact on brain metabolism. Moreover, neurons and glial cells exist in a mutual structural-functional relationship that depends on the peripheral supply of glucose as their major energy source. Insulin crosses the blood brain barrier (BBB), the insulin receptors are expressed in the brain, and as such insulin influences various neurological functions, apart from its effects on cerebral metabolism.

\section{Humoral links for brain metabolism}

There exists a close link between the neuronal function and the glucose metabolism mediated by insulin, and a documented role for insulin in neuronal growth, neuroplasticity and neuromodulation. Apart from this insulin serves several critical roles in the CNS under both various physiological and pathological conditions. The insulin receptors are widely expressed in the brain and influence a range of normal brain functions, such as reward, motivation, cognition, attention, and memory formation. The path physiological factors like oxidative stress and neuro-inflammation are also affected by insulin-mediated signaling.

In general, the cognitive performance is dependent on adequate glucose supply to the brain and optimal insulin action. Insulin, which regulates cerebral glucose metabolism, has also been shown to regulate hippocampus metabolism and is a mandatory component of hippocampally-mediated cognitive performance. Thyroid hormones (TH) which regulates systemic glucose metabolism and is also involved in regulation of brain glucose metabolism. TH also has interactions with insulin signaling. There are links between $\mathrm{TH}$, insulin, cognitive function, and brain glucose metabolism, and $\mathrm{TH}$, thus, modulates memory processes, in part by modulation of central insulin signaling and glucose metabolism [15].

In individuals exposed to excessive stress, there occurs chronic activation of the hypothalamic-pituitary-adrenal axis, resulting in the overproduction of stress/glucocorticoid hormones. This influences insulin action, associated with hyperinsulinemia and may lead to IR, and alters cerebral glucose metabolism. The exogenous administration of glucocorticoid is also associated with hyperinsulinemia and IR, and may affect cerebral metabolism.

\section{Regulation of cerebral glucose metabolism}

The glucose entry into the brain is by facilitated diffusion across the BBB. Further, there is evidence that the glucose transport adapts to the changes in cerebral metabolism, neural activation and changes in plasma glucose levels [16]. The brain, too, plays an important role in the maintenance of glucose homeostasis. The glucose-sensing neurons which are located in ventromedial hypothalamus and arcuate nuclei, respond to physiologic changes in extracellular glucose [17]. The neurons whose activity is regulated by glucose are distributed in various brain regions. There are glucose-excited (GE) neurons which increase while glucoseinhibited (GI) neurons decrease their action potential frequency as interstitial brain glucose levels change [18].

In the brain, glucose is either oxidized to produce ATP or used to synthesize glycogen and store it in astrocytes. Glycogen is an important source of glucose in brain and able to prevent hypoglycaemia and ensure a continuous supply of glucose to maintain normal neuronal function. The astrocytes glycogen metabolism, thus, has important implications for the functioning of the brain [19]. During hypoglycaemia and during periods of intense neuronal activity, when the energy demand exceeds supply, astrocytes glycogen is converted to lactate and transported to the 
neurons. Thus, glycogen from astrocytes functions as a protective reserve against hypoglycaemia and ensures neuronal preservation. The glycogen turnover is slow under basal conditions and the glycogenolysis maintains a high level of glucose-6-phosphate in astrocytes to maintain feedback inhibition of hexokinase, thereby diverting glucose for use by neurons. The astrocytes are able to influence the global ratio of oxygen to glucose utilization. It has important roles in astrocytes energetic, including glucose sparing, control of extracellular $\mathrm{K}+$ level, oxidative stress management, and memory consolidation [20].

\section{Insulin in normal and altered brain metabolism}

The insulin receptors are widely expressed in the brain and insulin influences a range of brain functions, such as reward, motivation, cognition, attention, and memory formation. It affects the exigencies like oxidative stress (OS) brought about by reactive oxygen species (ROS) and neuro-inflammation (NI) brought about by cellular stress, cytokines release, cellular damage and repair. The OS and NI, both have metabolic and neurologic consequences. Further, there is evidence that metabolic and neurologic disorders may share common pathophysiological mechanisms. Critical effectors of this association include alterations in energy metabolism, OS, NI, insulin resistance (IR) and corticosteroid signaling, as well as imbalances in cytokines and adipokines. The deregulation of insulin signaling leads to cognitive dysfunction and may lead to development of several neurodegenerative diseases including $\mathrm{AD}$.

With aging, as documented by animal studies, the intrinsic brain tissue changes alter the cellular bioenergetics and hamper the brain's ability to cope with metabolic stress [21]. When there is glucose deprivation, the brain becomes dysfunctional and may be permanently damaged. Here, the glucose stored as glycogen within astrocytes is of potential importance for tolerance of hypoglycaemia. Uncontrolled diabetes has a variety of adverse effects upon brain metabolism and function. Many aspects of brain function may be indirectly linked to cerebral glucose metabolism, and include neurotransmitter metabolism, cerebral blood flow, blood-brain barrier and micro vascular function [22].

\section{Challenges to the Altered Cerebral Metabolism}

Normally, an increase in neuronal metabolism is associated with neurotransmission-associated functions, such as restoration of ion gradients caused by action potentials, post-synaptic currents, and transport of glutamate into vesicles [23]. The astrocytes are important source of glycogen and provide energy for neurotransmission besides routine housekeeping tasks, like the production and action of modulators of neuronal activity and of synaptic plasticity, supply of antioxidant molecules and neurotrophic factors necessary for adequate brain function, and regulation of blood flow and volume.

\section{Hyperglycemias in T1DM}

The most common cognitive deficits observed in T1DM patients are slowing of information processing speed and worsening of psychomotor efficiency [24]. Other common deficits include deficits in vocabulary, general intelligence, vasoconstriction, attention, somatosensory appreciation, motor speed and strength, memory, and executive function [25].

The glycemia control appears to play a role in cognitive performance in patients with T1DM and with better glycemia control there is improvement in functions such as psychomotor efficiency, motor speed, attention, verbal IQ scores, memory, and academic achievement [26]. The 18-yr follow-up the Diabetes Control and Complications Trial (DCCT) showed that the T1DM patients with mean glycated haemoglobin (HbA1c) less than $7.4 \%$ performed significantly better on tests of motor speed and psychomotor efficiency than those subjects with a mean HbA1c greater than $8.8 \%$.

During acute hyperglycemias in patients with both T1DM and T2DM, there is slowing of cognitive function, increased number of mental subtraction errors and loss of focus, slowed speed of information processing, decreased attention, and impaired working memory [27]. A recent meta-analysis, which included 33 studies examining cognitive function in adult subjects with T1DMdocumented significant reductions in overall cognition, fluid and crystallized intelligence, speed of information processing, psychomotor efficiency, visual and sustained attention, mental flexibility, and visual perception in subjects with T1DM compared with controls [28]. There was no difference in memory, motor speed, selective attention, and language.

Although complications like retinopathy and nephropathy usually require years of diabetes before becoming clinically apparent, the onset of cognitive impairment has been found to occur early in patients with T1DM and deficits in cognitive function have been detected as early as 2 years after diagnosis in children with T1DM. Further, six years after diagnosis, these same subjects had impaired attention, IQ, processing speed, long-term memory, and executive function compared with controls. The age of onset of T1DM may also contribute to the presence of cognitive dysfunctions. Those who developed T1DM at less than 4 years of age had impaired executive skills, attention, and processing speed, compared to those that were diagnosed after 4 years of age [29].

\section{Hyperglycemias in T2DM}

The hyperglycaemia characterizes T2DM and has been linked to its chronic and acute complications. Cognitive dysfunction occurs in longstanding disease especially with poor glycemia control [30], and the patients with T2DM have cognitive impairments in psychomotor speed, executive function, processing speed, complex motor functioning, verbal and working memory, immediate and delayed recall, verbal fluency, visual retention, and attention [31]. But, the impact of these neurocognitive deficits on the activities of daily living (ADL) is variable. About $17.5 \%$ of elderly patients with T2DM suffered with moderate to severe deficits in ADL, $11.3 \%$ had cognitive impairment, and $14.2 \%$ had depression [32]. In general, the patients with mini-mental status exam scores less than 23 
fare worse on measures of self-care and ability to perform ADL, and have increased rates of hospitalization when compared with controls [33].

These patients have slower walking speed, lack of balance and increased rate of falls, depression affecting cognitive function and $\mathrm{ADL}$, and increased incidence of AD and vascular dementia [34]. The glycemia control in T2DM patients, in general, appears to play an important role in determining the degree of cognitive dysfunction and a good blood glucose control improves the outcome [35]. A linear relationship between poor performance on the California Learning Test and elevated glycosylated haemoglobin has also been noted in older patients with T2DM [36]. The acute hyperglycaemia also leads to impairments in mood state and cognitive performance in patients with T2DM [37]. It has been documented that those not having T2DM but with impaired glucose tolerance, also suffer with a risk for cognitive dysfunction [38].

\section{Hypoglycaemia and cognitive dysfunction}

The repetitive episodes of moderate to severe hypoglycaemia in both T1DM and T2DM lead to cognitive impairment. During acute hypoglycaemia episodes, the immediate verbal, visual, working and delayed memories are impaired as are the visual-motor and visualspatial skills, and there is global cognitive dysfunction. In a study in T1DM patients by Warren et al. [39] both prospective memory and recall - immediate and delayed memories, were shown to be affected as result of hypoglycaemia episode [39]. The effect of repetitive hypoglycaemia on subsequent cognitive function, though, is not clear, and in a study by Jacobson et al, no clear-cut association between multiple severe episodes of hypoglycaemia and impaired cognitive function in patients with T1DM was documented in an 18-year follow-up [40]. This lack of association between severe hypoglycaemia and cognitive impairment has been noted by earlier studies also [41].

But, other studies have documented the association between frequent hypoglycaemia and cognitive abnormalities as on MRI imaging [42]. Another study in children with more frequent episodes of hypoglycaemia $(<70 \mathrm{mg} / \mathrm{dl})$, in fact documented an increased memory and verbal scores, and overall better academic achievement when compared with less well-controlled children with T1DM [43]. Also, a 16-year follow up of T1DM patients documented that severe hypoglycaemia at a young age affected the cognitive function [44]. It appears that the children with more hypoglycaemia episodes were having overall better glycemic control, which may offset the neurocognitive damage from hypoglycaemia. Also, the severity of the hypoglycaemia as well as the less susceptibility of young brains to hypoglycaemic injury may explain the discrepancy.

\section{Comparison of hypoglycaemia episodes in T1DM and T2DM}

Though the repetitive episodes of moderate to severe hypoglycaemia have been implicated as an etiology of cognitive decline in T1DM and T2DM, the association between improved diabetes control and less cognitive dysfunction, appears to be more clear-cut in patients with T2DM than those with T1DM [45]. This may be because of the difference in natural history of T1DM and T2DM. Also, there is an increased incidence of dementia in patients with T2DM (but not in T1DM), compared with the rest of the population.

A large-scale, longitudinal cohort study documented that severe hypoglycaemia was a risk factor for dementia in elderly subjects [46]. Further, the hypoglycaemia in the elderly is often combined with pre-existing atherosclerosis, making neuronal damage more likely. On the other hand, the impaired cognitive function is likely to increase the risk of severe hypoglycaemia [47].

\section{The Pathophysiology of Cognitive Alteration in DM}

\section{The contributors to cognitive decline}

There are various factors that contribute to development of cognitive decline in patients with DM (Fig 2). There are many hypotheses with supporting evidence from animal studies and short-term as well as long-term clinical studies. Adults with diabetes have also been found to have structural changes, including atrophy and leukoariosis on MRI [48]. In large epidemiological studies, dementia seems to be more common in adults with diabetes (primarily T2DM) than in adults without the disease.

The extremes in glycemia experienced by patients with T1DM and advanced T2DM have an impact of brain structure and function [49]. The chronic exposure to recurrent hyperglycaemia and hypoglycaemia has also been linked to alterations in brain structure and function [50]. The children with T1DM experiencing episodes of severe hypoglycaemia at an age less than 5 years have reduced performance on measures of spatial intelligence and delayed recall compared to children who did not experience severe hypoglycaemia at a young age, and both sets of children with T1DM have reduced measures of verbal intelligence compared with nondiabetic sibling controls. Structural changes in children with T1DM have been identified and hyperglycaemia and hypoglycaemia affect different regions differently [51].

The role of hyperglycaemia: Both in T1DM and T2DM, the hyperglycaemia is related to cognitive dysfunction. There are various mechanisms (Figure 2):

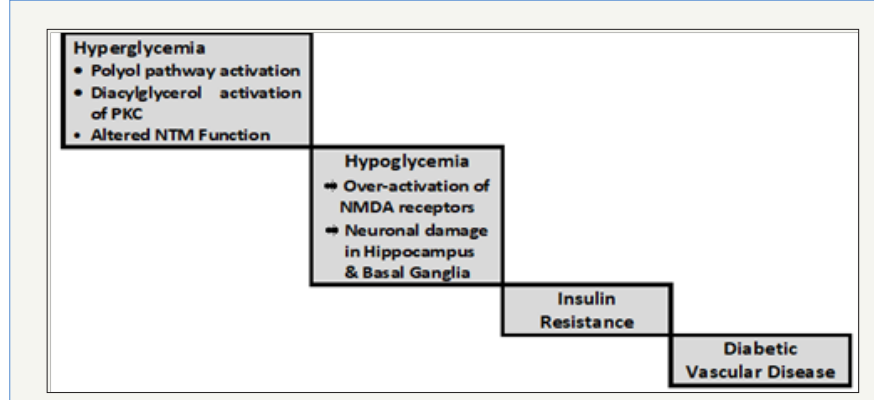

Figure 2: Diabetes mellitus -the contributors to cognitive decline.

A. Polyol (sorbitol-aldose reductase) pathway activation: In this pathway glucose is reduced to sorbitol, which is subsequently 
oxidized to fructose. The activation of the polyol pathway results in a decrease of reduced NADPH and oxidized NAD+; which are necessary cofactors in redox reactions [52]. Further, the decreased concentrations of these NADPH leads to decreased synthesis of reduced glutathione, nitric oxide, myo-inositol, and taurine and increased concentrations of ROS [53], include superoxide. The ROS cause neuro-inflammation and neuronal damage [54].

The Sorbitol cannot cross cell membranes, accumulates and leads to increased cellular osmotic pressure. Further, the increased sorbitol glycates proteins and forms advanced glycation end-products (AGEs), which activates of receptors for advanced glycation end-products (RAGE) and leads to inflammatory response in neurons and glial cells, and damage to white matter and myelin [55]. The patients with DM and AD both have been found to have increased N-carboxy-methyl-lysine, a type of AGE [56].

B. Diacylglycerol activation of protein kinas C: The PKC activation leads to increased glucose shunting in the hexosamine pathway. In the rodent studies, the brain expression of protein kinas $C-\alpha$ has been shown to be significantly increased in untreated diabetic rats compared with those from treated and control groups [57]. This is also supported by the observation that cerebral chitin an $\mathrm{N}$-acetyl-glucosamine polymer produced via the hexosamine pathway, is increased in human subjects with Alzheimer's disease on autopsy [58].

C. Altered Neurotransmitter Function: In addition to hyperglycaemic-induced end organ damage, altered neurotransmitter function has been observed in animal diabetic models and shown to contribute to cognitive dysfunction [59]. In diabetic rats, there is an impairment of long-term potentiation in neurons rich in receptors for the neurotransmitter N-methyld-aspartate (NMDA), which contributes to learning deficits. In addition, there is decreased acetylcholine, serotonin turnover, dopamine activity, and increased nor epinephrine in the brains of animal models with diabetes. Experimentally, these changes reversed with insulin.

The role of hypoglycaemia: The patients with T1DM and advanced T2DM are at risk for hypoglycaemia because the counterregulatory response becomes impaired [60]. These patients neither reduce endogenous insulin secretion in response to falling blood sugar, nor can respond to hypoglycaemia by increasing glucagon secretion, because the $\alpha$-cell and $\beta$ cell dysfunction. The only preserved defence is an increase in epinephrine secretion and activation of the sympathetic nervous system, but recurrent episodes of hypoglycaemia drive down the glucose level that elicits this response. As a result, patients with recurrent hypoglycaemia may not have general symptoms of hypoglycaemia, and become unconscious from neuroglycopenia.

The underlying mechanisms may be that recurrent hypoglycaemia alters glucose sensing in the thalamus or any other brain region. The cortex, basal ganglia, and hippocampus are especially vulnerable to hypoglycaemia, which selectively damages neurons with sparing of astrocytes and oligodendrocytes.
The brain compensates for recurrent hypoglycaemia by increasing brain glucose transport so that more glucose passes from the blood into the brain during subsequent episodes of hypoglycaemia. In support, in animal models, glucose transporter proteins and glucose transport are shown to be up-regulated in response to hypoglycaemia.

In general, the impaired hypoglycaemia awareness occurs in up to $20 \%$ of patients with T1DM. The therapies designed to bring glucose levels close to the no diabetic range, have increased risk of severe hypoglycemia. The young children with T1DM are particularly susceptible to cerebral complications of hypoglycaemia. The hypoglycaemia during early nocturnal sleep, a time when consolidation of memories occurs, is likely to lead to impaired memory and cognitive dysfunction [61]. The hypothesis that hypoglycaemia-induced neuronal damage occurs as a result of over-activation of a subtype of the excitatory neurotransmitter NMDA receptor [62] has been supported by the observation that an NMDA receptor antagonist prevents neuronal necrosis, which can be a potential therapy for hypoglycaemia-induced brain damage [63].

Patients with T1DM, experience on average 2 hypoglycaemic episodes per week and 1 severe episode of hypoglycaemia each year [64]. Because the brain depends almost exclusively on glucose, recurrent hypoglycaemia may be a threat for cognitive dysfunction and cerebral damage, and the patients with T1DM may be at increased risk for accelerated cognitive decline and possibly for dementia [65]. But, the patients with T1DM are able to endure moderate hypoglycaemia and recurrent episodes of severe hypoglycaemia do not appear to risk cognitive function impairment [66]. The recurrent hypoglycaemia appears to induce protective adaptations in cerebral glucose metabolism [67] and there has been no evidence of substantial long-term declines in cognitive function in a large group of patients with T1DM followed for an average of 18 years, despite episodes of recurrent severe hypoglycaemia [68].

The role of insulin resistance: There is evidence that insulin resistance, a factor contributing to the onset of T2DM, may play a role in the pathogenesis of $\mathrm{MCI}$ and $\mathrm{AD}$, which have been found to be approximately 1.2- to 1.7-fold higher in patients with T2DM compared with a control population [69]. On the other hand, T2DM is also more common in patients with AD [70]. The insulin resistance in T2DM has been correlated to increased neuroinflammation, inflammatory markers and macro vascular disease. It also causes disruption of the hypothalamic-pituitary adrenal axis and increased cortisol levels which may contribute to cognitive dysfunction. Finally, the insulin resistance contributes to cognitive dysfunction by affecting the metabolism of APP and $\beta$-amyloid leading to accumulation of $\beta$-amyloid and promoting the formation of senile plaques.

Though the exact mechanism through which insulin resistance affects cognitive function is not known, it appears that it is through the cholinergic activity and memory formation. The impairment in central cholinergic activity is also thought to contribute to the pathogenesis of $\mathrm{AD}$ [71]. The patients with $\mathrm{AD}$ have a 
reduced cerebral glucose uptake and reduced number of glucose transporters in frontal cortex, hippocampus, caudate nucleus, parietal, occipital, and temporal lobe as compared with controls on autopsy studies [72]. The reduction in glucose uptake appears to have a direct effect on hippocampal function. In fact, glucose administration with a rise in endogenous insulin levels or insulin administration AD patients have been shown to alter behaviour, perhaps by enhancing cholinergic activity [73]. This has led to the hypothesis that in $\mathrm{AD}$, cerebral insulin resistance requires higher levels of insulin to facilitate memory.

Further, the relationship between insulin resistance and cognitive dysfunction in $\mathrm{AD}$ appears to depend on the presence or absence of the APOE- $\varepsilon 4$ allele. The presence of the APOE- $\varepsilon 4$ allele is associated with an increased incidence of $\mathrm{AD}$ [74]. But, it appears that insulin resistance/T2DM and APOE- $\varepsilon 4$ allele positivity are distinct and separate risk factors for the development of $\mathrm{AD}$ [75]. This hypothesis is supported by the fact that those with T2DM have a low incidence of the APOE- $\varepsilon 4$ allele. The association between insulin resistance and $\mathrm{AD}$, and peroxisome proliferatorsactivated receptor- $\gamma$ (PPAR- $\gamma$ ) has also been investigated [76]. The trials have demonstrated PPAR- $\gamma$ agonist rosiglitazone to have a beneficial effect on memory and cognitive function in patients with AD., probably by reducing serum glucocorticoid, decreasing glial inflammation, protecting against $\beta$-amyloid-induced neurodegeneration, decreasing $\beta$-amyloid production, increasing $\beta$-amyloid degradation, and decreasing phosphorylation of tau proteins.

The role of vascular disease: Patients with DM have a 2- to 6-fold increased risk of vascular disease and thrombotic stroke. There occurs thickening of capillary basement membranes in cerebral vasculature, which is the hallmark of diabetic microangiopathy, leading to a decreased global cerebral blood flow [77]. Interestingly, the decreased rate of cerebral blood flow in patients with $\mathrm{DM}$ is akin to that encountered in $\mathrm{AD}$ [78].

The decrease in cerebral blood flow, coupled with the stimulation of the thromboxane A2 receptor, contributes to the inability of cerebral vessels to adequately vasodilate, and increases the likelihood of ischemia. The coexistence of ischemia and hyperglycaemia are particularly detrimental to the brain. One potential mechanism through which hyperglycaemia could potentiate ischemic damage is lactate accumulation leading to cellular acidosis and worsening injury [79]. Another mechanism is the accumulation of glutamate in the setting of hyperglycaemia and ischemia [80]. Glutamate, an excitatory amino acid neurotransmitter, has been shown to cause neuronal damage in the brain. Again, there is lack of C-peptide in patients with T1DM, which may worsen cognitive impairment through its deficient action on the endothelium, as suggested by animal studies [81].

\section{Impact of longstanding T1DM and T2DM}

With aging, intrinsic brain tissue changes in cellular bioenergetics may hamper the brain's ability to cope up with metabolic stress. This has been supported by animal studies. With aging utilization of glycogen stores is increased during low glucose, particularly in hippocampus, indicating both inefficient metabolism and increased demand for glucose [82].

Cognitive impairment in T1DM: Adults with T1DM have been found to have reduced performance on tests of information processing, psychomotor efficiency, attention, visuo-constructive ability, and mental flexibility [83]. These cognitive domains are believed to reside primarily in white matter, and the changes in neurocognitive performance in adults with T1DM can be linked to changes in white matter microstructure. The diabetes, in general, leads to changes both in white matter microstructure and in gray matter density in regions with high connectivity.

Cognitive impairment in T2DM: In the T2DM Patients, the epidemiological evidence shows that the risk of MCI and dementia increases with duration of disease. There was no evidence that any specific treatment or treatment strategy for T2DM can prevent or delay cognitive impairment. The comparison of intensive with standard glycemia control strategies shows that the strategies do not differ in their effect on global cognitive functioning over 40 to 60 months [84].

Thus, T2DM is associated with cognitive deficits, mainly affecting learning, memory and information processing speed, MCI and accelerated cognitive decline, and increased risk of dementia, particularly AD [85]. Further, T2DM is associated with various cerebral abnormalities detected on MRI and other techniques of neuroimaging. In T2DM most cerebral changes are located in the frontal and/or temporal lobe and the MRI studies show gray matter loss and medial temporal lobe atrophy as are associated with AD. T2DM is also known to increase the risk of developing AD. These results suggest that $\mathrm{T} 2 \mathrm{DM}$ to some extent be linked to $\mathrm{AD}$ and that diabetes and AD might share similar mechanisms underlying cognitive decline [86].

Cerebral structural and functional abnormalities in T2DM

\begin{tabular}{|c|c|c|c|c|c|c|c|c|}
\hline \multicolumn{5}{|c|}{ Cerebral Atrophy } & \multicolumn{3}{c|}{ Small Vessel Disease } \\
\hline $\begin{array}{c}\text { Neuronal } \\
\text { Dysfunction } \\
\text { and }\end{array}$ & $\begin{array}{c}\text { Reduced } \\
\text { connectivity } \\
\text { in DMN and }\end{array}$ & $\begin{array}{c}\text { Altered ADC in } \\
\text { Hippocampus } \\
\text { \& other brain } \\
\text { connectivity }\end{array}$ & $\begin{array}{c}\text { Altered } \\
\text { Networks } \\
\text { Activation }\end{array}$ & $\begin{array}{c}\text { Altered } \\
\text { and } \\
\text { Metabolic }\end{array}$ & $\begin{array}{c}\text { White } \\
\text { Matter } \\
\text { and NTM }\end{array}$ & $\begin{array}{c}\text { Micro- } \\
\text { hemo- }\end{array}$ & $\begin{array}{c}\text { Lacunar } \\
\text { Lesions } \\
\text { Abnor- }\end{array}$ & $\begin{array}{c}\text { Silent } \\
\text { Brain }\end{array}$ \\
rhages & malities & Infarcts \\
Functions & (WMLs) & & & \\
\hline
\end{tabular}

Figure 3: The cerebral structural and functional abnormalities in T2DM. 
Cerebral atrophy: Cerebral atrophy is the shrinkage of brain tissue, which occurs as a result of neurodegenerative processes, such as the loss of neurons and their interconnections. Associations have been found between brain atrophy and decreased performance in various cognitive domains including memory, attention and executive function, as well as processing, sensory and motor speed. Also the accelerated progression of atrophy in T2DM is found to be related to cognitive decrements (Figure 3).

Neuronal dysfunction: Neuronal dysfunction refers to impairments of the neurons, reduced functional activity of certain brain regions and the connectivity between various brain regions. The decreased neuronal activity is a manifestation of cerebral hypo perfusion and oxygenation, and alterations in the neurons including apoptosis and in the white matter. The neuronal activity has been shown to be abnormal in patients with T2DM [87].

Functional connectivity and activation: There is reduced functional connectivity in the default mode network (DMN), i.e., the network of active brain regions when the brain is at rest and the participant is not focusing on anything particular, in patients with T2DM [88]. Further, reduced functional connectivity between the posterior cingulated and the medial frontal gyri and other regions, and the hippocampus and other regions including the medial frontal cortex has been documented. There is altered brain activation in patients with T2DM during a memory task, especially in taskrelated regions of the DMN, frontal cortex, parietal cortex and the fronto-parietal network. Furthermore, the reduced functional connectivity and activation have been related to neuropsychological scores, glycated haemoglobin, and lipid profile suggesting a major role of glucose and lipid metabolism. The functional MRI studies consistently have documented evidence of altered neuronal activity or functional connectivity in patients with T2DM [89].

White matter tract abnormalities: There is altered integrity of axonal bundles, with an increase in apparent diffusion coefficient (ADC) found in the hippocampus and number of brain regions. The elevated ADC has been associated with reduced neuronal cell packing and increased extracellular space, possibly due to failure of neurogenesis or cell loss, manifesting as cerebral atrophy. There are other micro structural abnormalities in various brain regions in T2DM and include educed fractional anisotropy (FA) in the white matter mostly concentrated in frontal and temporal regions. The temporal lobe abnormalities have been associated with impaired memory.

Network alterations: There are altered network and structural connectivity, of both local and global kinds, in T2DM on tractography which are associated with impaired memory and processing speed. Elevated ADC and reduced FA are found in various tracts, including the superior longitudinal fasciculus, uncinate fasciculus, inferior longitudinal fasciculus, corpus callosum and cingulum bundle. Moreover, the altered hippocampal white matter connectivity is associated with memory decrements in T2DM. In these patients, the diffusion MRI studies show evidence of white matter microstructure, tract, and network abnormalities.
Metabolic dysfunction: In a recent study higher GABA+ levels and high HbA1c levels were correlated with decreased cognitive performance in T2DM patients. They also had alterations in the GABAergic neurotransmitter system, which indicates the involvement of an underlying metabolic mechanism [90].

Small vessel disease: The cerebral small vessel disease (cSVD) affects the small arteries, arterioles, venues and capillaries of the brain and manifests as white matter lesions, micro-hemorrhages, silent brain infarcts and lacunar abnormalities [91]. The accelerated vascular changes in T2DM lead to cerebral hypo perfusion, which remains statically significant after correction for cerebral atrophy [92]. Further, the hypo perfusion signifying the involvement of a vascular system varies with the brain regions [93].

White matter lesions: WMLs are typically observed as regions of bright, high-signal intensity in the white matter depicted on T2weighted and FLAIR MRI images. More specific, deep subcortical WMLs and periventricular WMLs are found in patients with T2DM. The periventricular WMLs are associated with the rate of cognitive decline in elderly non-demented individuals. WMLs, in general, are related to impaired cognition in T2DM, especially in the domains of processing speed, memory, attention and executive functioning, and motor speed.

Micro hemorrhages: Cerebral micro-hemorrhages result from focal leakages of small blood vessels. They are often found incidentally on MRI, but their prevalence increases with age and thought to play a role in cognitive decline [94].

Lacunar abnormalities: Lacunes are small areas of infarction (3-15mm in diameter) resulting from ischemia caused by occlusion of the small penetrating branches of cerebral arteries and are associated with cognitive impairment [95]. Cerebral infarcts (i.e., lacunar, cortical, subcortical infarcts, or infarcts in general) have been observed in patients with T2DM. They lead to decreased performance in various cognitive domains, including processing speed, sensory speed, memory, executive function, and global cognition.

Silent brain infarcts: SBIs are often clinically asymptomatic. They are visible as focal lesions (2-5 $\mathrm{mm}$ in diameter) on MRI and are associated with cognitive deficits. Patients with T2DM often display SBIs, which are also related to impaired cognitive performance. The number of SBIs and their progression has been linked to decrements in motor speed, attention and executive functioning.

\section{Mechanisms for accelerated cognitive decline in DM}

Various mechanisms have been considered for an association between DM and accelerated cognitive dysfunction, and include atherosclerosis, microvascular disease, advanced protein glycation and oxidative stress as a result of glucose toxicity, insulin resistance and abnormal insulin action and aging and genetic factors [96].

There are some differences in the aspects of cognitive functions that are affected in T1DM and T2DM. Such aspects as information 
processing, psychomotor efficiency, attention, vasoconstriction and mental flexibility are primarily impaired in T1DM. Whereas, in T2DM, Psychomotor speed, executive function and memory are primarily affected [97]. In elderly T2DM patients, walking speed is reduced, balance is impaired, risk of falls is increased and fractures are more frequent. The executive dysfunction has been associated with inability to carry out lower-extremity tasks [98].

Glycemic control and cognitive decline: The glycemic control and duration of DM, both are important parameters relating to cognitive decline. It reported by Bruce et al, the number of years of diabetes duration and atherosclerosis were important risk factors for dementia [99]. The ACCORD-MIND study observed a 0.14-point drop in Mini-Mental State Examination (MMSE) score for each 1\% increase in $\mathrm{HbA1c}$, and this was associated with impaired aspects of cognitive function such as psychomotor speed, memory and executive function, suggesting a significant negative association between $\mathrm{HbA1c}$ level and cognitive function [100]. A study by Yaffe et al. [101] reported a fourfold increase in cognitive impairment in subjects with $\mathrm{HbA} 1 \mathrm{c} \geq 7 \%$, as compared with those with $\mathrm{HbA1c}$ $<7 \%$, the majority of the subjects in the study were not diabetic [101]. Also, the DCCT/EDIC study, which was carried out in T1DM patients, reported that motor speed and psychomotor efficiency were reduced in a group with $\mathrm{HbA} 1 \mathrm{c} \geq 8.8 \%$, as compared with a group with $\mathrm{HbA1c} \leq 7.4 \%$ [102].

It appears that these discrepancies in the findings of various studies arise from the complex interaction of factors that affect cognitive function, such as the subjects selected, age group and duration of diabetes, presence of complications affecting large and small vessels, and hypertension. Also, there appears to be a certain threshold above which abnormal blood glucose levels cause cognitive impairment [103]. With intensive treatment, hypoglycaemia readily occurs, which has a detrimental influence on cognitive impairment [104]. Taking the findings of together, keeping HbA1c 7\% should maintain a good state of cognitive function.

An important study documented that diurnal variation in blood glucose was more closely associated with MMSE scores and other aspects of cognitive function than $\mathrm{HbA1c}$, fasting blood glucose and postprandial blood glucose [105]. Also, the Hisayama study found that an increase in postprandial blood glucose was more closely associated with cognitive impairment than an increase in fasting blood glucose [106]. There have also been studies on a relationship between metabolic syndrome and cognitive decline [107]

The anti-diabetic therapy and cognitive function: The studies document that glucose control leads to improvement in cognitive function and the treatment with hypoglycaemic agents can achieve a short-term improvement in cognitive function [108]. In a 24-week study in which rosiglitazone, a thiazolidinedione, or glibenclamide, a sulfonylurea, was combined with metformin, it was documented that improved blood glucose was associated with improvement in working memory [109]. In another study, oral hypoglycaemic agents were more effective when the duration of disease was longer, and that multiple drug therapy was better at improving cognitive function than immunotherapy [110]. Regarding therapeutic agents, it has been shown that insulinsensitizing compounds, such as the thiazolidinedione, rosiglitazone and pioglitazone, are effective in improving cognitive function [111]. In addition, the intranasal administration of insulin has been documented to be effective when its action in the brain is insufficient [112]. The agents enhancing incretin effects may have beneficial effects on neurons and disruption of brain insulin signaling, as documented in animal models [113].

In a large-scale cohort study in elderly females, however, it was noted that diabetes enhanced cognitive decline over 2 years of follow up and there was no difference between the subjects treated with oral hypoglycaemic agents and non-diabetic subjects [114]. The cognitive decline has also been reported in elderly patients receiving insulin therapy [115]. The explanation put forward is that in the elderly DM patients, probably the irreversible cognitive impairment has already set in. In other studies, insulin treatment in $\mathrm{DM}$ patients with $\mathrm{AD}$ has been shown to have beneficial effects on memory improvement and performance.

Cerebral glucose metabolism and insulin's role: The normal glucose metabolism-The brain, utilises about $25 \%$ of total body glucose mediated by insulin and the neurons require continuous supply of glucose from blood [116]. In essence, the brain increases its utilization of glucose upon activation and a large proportion of energy in the brain is consumed for the generation of action potentials and postsynaptic potentials following synaptic events, and the maintenance of ion gradients and neuronal resting potential. Additionally, glucose metabolism provides the energy and precursors for the biosynthesis of neurotransmitters and for other energy demands of brain not related to signaling [117]. The astrocytic glycogen appears to be directly relevant for learning and the glycolytic end product lactate plays a role in long-term memory formation. The astrocytic glycogen supplies carbon for synthesis of glutamate during learning. A considerably larger amount of energy is spent in the grey matter compared with the white matter [118].

Insulin and cognitive functions - There are a large number of insulin receptors in cerebral cortex and the hippocampus, which play a central role in memory. Insulin induces the release of $\beta$-amyloid peptide $(A \beta)$ in cells to the cell exterior, and also promotes the expression of insulin degrading enzyme (IDE). As insulin is degraded by IDE, in the high insulin state, IDE is consumed and its amount decreases, resulting in accumulation of $A \beta$. The latter has been related to the progression of the cognitive impairment [119].

The insulin receptors are distributed throughout the brain and the insulin-sensitive glucose transporters (e.g. glucose transporter [GLUT]-4 and GLUT-8) are present in both neurons and astrocytes [120]. Insulin plays an important role in the regulation of normal emotional and memory function, and learning, as well as regulates feeding behaviour. In addition, insulin also plays an important role 
in dopamine-mediated reward circuits involved in the motivating, rewarding and reinforcing cognitive functions. The chronic hyperinsulinemia, as in T2DM and obesity, down-regulates insulin receptor expression and is accompanied by insulin resistance. The cerebral glucose metabolism and deregulation of insulin's intracellular effects have been implicated in the pathogenesis of cognitive disorders. The support comes from AD rodent models where intranasal insulin treatment produced beneficial effects on memory performance and attention. Thus, the altered insulin homeostasis, thus, appears to be important in the development of neurodegenerative diseases such as $\mathrm{AD}$ [121].

A cohort study in middle-aged adults documented an association between hyperinsulinemia and cognitive decline [122]. Further, in the Hisayama study, autopsy findings showed that hyperinsulinemia and hyperglycaemia as a result of insulin resistance enhanced neurotic plaque formation [123]. Furthermore, in a 12 years follow-up study in elderly men, it was reported that a reduction in insulin secretion, but not in insulin sensitivity, was associated with the onset of Alzheimer's disease [124]. Insulin-mediated signaling pathways appear to influence $\mathrm{AD}$ outcome by clearing $\beta$-amyloid from the brain. In the CNS, insulin increases dopamine transporters in substantial nigra and lowers the plasma concentrations of the amyloid precursor protein, implicated in the development of AD. In addition, the mouse models with brain-specific deletions of insulin signaling molecules display increased levels of phosphorylated tau, another protein implicated in AD.

Disturbed glucose metabolism and Neurodegeneration - The brain has high energy demand and neurons are largely intolerant of inadequate energy supply. The disrupted metabolism, oxidative stress and bioenergetic stress, thus, have been linked to apoptosis through cell death pathways and autophagy, which forms the pathophysiological basis for various neurodegenerative disorders [125]. Hexokinase II (HKII), is a hypoxia-regulated HK is form in the brain and has been shown to control neuronal survival depending on the metabolic state. The HKII activity acts as a molecular switch that protects against neuronal cell death in the presence of oxidative stress, but increases neuronal cell death under glucose deprivation [126]. Another factor, GK (also known as hexokinase IV) also has a role in regulating neuronal viability depending on the metabolic state in select glucose sensing neuronal populations.

Both human studies and animal models suggest that disturbed cerebral glucose metabolism, as in T2DM, leads to cognitive impairment and AD progression [127]. The disrupted central glucose sensing, defective hypothalamic circuits and deregulated glucose metabolism in DM can potentially injure the brain through both hypo- and hyperglycaemia [128]. Further, the disturbances of insulin-mediated signaling have both metabolic and neurologic consequences, accentuated by stress and neuro-inflammation. These pathophysiological concepts form the basis of association of accelerated cognitive decline with DM, also evidenced by MRI studies showing gray matter loss [129] andothercerebral changes often located in the frontal and temporal lobes [130].

\section{Conclusion - Finding the Solutions}

\section{Way out of the research smog}

Various research studies, experimental as well as clinical, sometimes provide varying results creating research smog. It is, thus, important to dissect and analyse data for uniformity. As related to the subject matter of the current paper, collectively, the data support the notion that cognitive decline and $\mathrm{AD}$ in setting of DM may be conceptualized as a metabolic disorder, with progressive impairment of the brain's capacity to utilize glucose and respond to insulin and IGF-1. Further, the studies have documented an overlap between metabolic disturbances and neuropsychiatric disorders and deregulation of insulin signaling leading to characteristic signs of neurodegenerative and cognitive impairment. Furthermore, the metabolic and neuropsychiatric disorders may share certain common pathophysiological pathways. Critical effectors of this association include alterations in cerebral energy metabolism, oxidative stress, neuro-inflammation, insulin resistance, and disruptive corticosteroid signaling, as well as imbalances in cytokines and adipokines.

\section{Applying research to find solutions}

A. The QOL issues in DM patients with cognitive decline: The cognitive decline affects ADL and QOL; it affects life expectancy as well. On the other hand, aging entails structural and functional changes in brain, accompanied with cognitive dysfunction [131]. Mild cognitive impairment is the stage before dementia, and when it is accompanied by DM, progression to dementia is accelerated [132]. Modest cognitive decrements have been reported to be already present at the early stage of T2DM [133]. In the National Health and Aging Trends Study, the baseline DM diagnosis was associated with decline on immediate and delayed word-recall and the Clock Drawing Test. In Cox proportional hazards models, DM also predicted incident dementia in older age groups at baseline. These findings support the notion that DM is associated accelerated cognitive decline [134].

B. Factors influencing cognitive function in diabetic patients: About half of all cases of AD are attributable to seven potentially modifiable risk factors - diabetes, midlife hypertension, midlife obesity, smoking, depression, low education level and physical inactivity [135]. There is preponderance of lifestyle-related diseases, such as metabolic syndrome, adiposity, dyslipidemia and hypertension in the middle aged diabetic patients [136]. Further, the DM is accompanied by IR and hyperinsulinemia. The IR, dyslipidemia and adiposity leads to a subclinical inflammatory state which has been related to a higher risk of cognitive decline and dementia, including vascular dementia and late onset AD [137].

It appears that in diabetic patients there is complex interaction of factors affecting cognitive function. The factors include age group and duration of diabetes, presence of other diabetic complications including vascular disease, and associated factors like hypertension, dyslipidemia and adiposity. Calorie restricted (CR) diets and diet plans for calorie restriction with adequate nutrition (CRAN) help in 
improving insulin sensitivity and IR, and decreasing dyslipidemia and adiposity [138]. There appears to be a certain threshold above which abnormal blood glucose levels cause cognitive impairment. DM-associated hyperglycaemia, per se, accelerates cognitive decline [139]. With intensive treatment, hypoglycaemia readily occurs, which has a detrimental influence on cognitive function. Inference from studies and data analysis suggests that keeping HbA1c $7 \%$ with avoidance of hypoglycaemia is desirable and helps to preserve cognitive function in patients with DM [140].

\section{References}

1. Ott A, Stolk RP, van Harskamp F, Pols HA, Hofman A, et al. (1999) Diabetes mellitus and the risk of dementia: The Rotterdam Study. Neurology 53(9): 1937-1942.

2. Bruce DG, Harrington N, Davis WA, Davis TM (2001) Dementia and its associations in type 2 diabetes mellitus: the Fremantle Diabetes Study. Diabetes Res Clin Pract 53(3): 165-172.

3. Areosa Sastre A, Vernooij RW, González ColaçoHarmand M, Martínez G (2017) Effect of the treatment of Type 2 diabetes mellitus on the development of cognitive impairment and dementia. Cochrane Database Syst Rev 6: CD003804.

4. Jacobson AM, Musen G, Ryan CM (2007) Diabetes Control and Complications Trial/Epidemiology of Diabetes Interventions and Complications Study Research Group. N Engl J Med 356(18): 1842-1852.

5. Musen G, Jacobson AM, Ryan CM, Cleary PA, Waberski BH, et al. (2008) Impact of diabetes and its treatment on cognitive function among adolescents who participated in the Diabetes Control and Complications Trial. Diabetes Care 31(10): 1933-1938.

6. Launer LJ, Miller ME, Williamson JD, Lazar RM, Gerstein HC, et al. (2011) Effects of intensive glucose lowering on brain structure and function in people with type 2 diabetes (ACCORD MIND): a randomized open-label Substudy. Lancet Neurol 10(11): 969-977.

7. Christman AL, Matsushita K, Gottesman RF, Mosley T, Alonso A, et al. (2011) Glycated haemoglobin and cognitive decline: the Atherosclerosis Risk in Communities (ARIC) study. Diabetologia 54(7): 1645-1652.

8. Ohara T, Doi Y, Ninomiya T, Hirakawa Y, Hata J, et al. (2011) Glucose tolerance status and risk of dementia in the community: the Hisayama Study. Neurology 77(12): 1126-1134.

9. Willis T (1675) Pharmaceuticerationali-ssivediatriba de medicament orumoperationibus in humanocorpore. E Theatro Sheldoniano MDC LXXV: ISBN: 978-1240416721, Oxford, UK

10. Menninger W (1935) Psychological factors in etiology of diabetes. J NervMent Dis 81: 1-13

11. Lustman PJ, Clouse RE (2005) Depression in diabetic patients: the relationship between mood and glycemic control. J Diabetes Complications 19(2): 113-122.

12. Mezuk B, Eaton WW, Albrecht S, Golden SH (2008) Depression and type 2 diabetes over the lifespan: a meta-analysis. Diabetes Care 31(12): 2383-2390.

13. Cheng G, Huang C, Deng H, Wang H (2012) Diabetes as a risk factor for dementia and mild cognitive impairment: a meta-analysis of longitudinal studies. Intern Med J 42(5): 484- 491.

14. Sonnay S, Gruetter R, Duarte JMN (2017) How Energy Metabolism Supports Cerebral Function: Insights from ${ }^{13} \mathrm{C}$ Magnetic Resonance Studies In vivo. Front Neurosci 11: 288.

15. Jahagirdar V, McNay EC (2012) Thyroid hormones role in regulating brain glucose metabolism and potentially modulating hippocampal cognitive processes. Metab Brain Dis 27(2): 101-111.
16. Rao J, Oz G, Seaquist ER (2006) Regulation of cerebral glucose metabolism. Minerva Endocrinol 31(2): 149-158.

17. Routh VH (2002) Glucose-sensing neurons: are they physiologically relevant? J Physiol Behav 76(3): 403-413.

18. Routh VH (2010) Glucose sensing neurons in the ventromedial hypothalamus. Sensors (Basel) 10(10): 9002-9025

19. Falkowska A, Gutowska I, Goschorska M, Nowacki P, Chlubek D, et al. (2015) Energy metabolism of the brain, including the cooperation between astrocytes and neurons, especially in the context of glycogen metabolism. Int J Mol Sci 16(11): 25959-25981.

20. Dienel GA, Cruz NF (2015) Contributions of glycogen to astrocytic energetics during brain activation. Metab Brain Dis 30(1): 281-298.

21. Galeffi F, Shetty PK, Sadgrove MP, Turner DA (2015) Age-related metabolic fatigue during low glucose conditions in rat hippocampus. Neurobiol Aging 36(2): 982-992.

22. McCall A (2004) Cerebral glucose metabolism in diabetes mellitus. Eur J Pharmacol 490(1-3): 147-158.

23. Sonnay S, Gruetter R, Duarte JMN (2017) How Energy metabolism supports cerebral function: insights from ${ }^{13} \mathrm{C}$ magnetic resonance studies in vivo. Front Neurosci 11: 288.

24. Cukierman Yaffee T (2009) The relationship between dysglycemia and cognitive dysfunction. Curr Opin Investig Drugs 10(1): 70-74.

25. Cukierman Yaffe $T$ (2014) Diabetes, dysglycemia and cognitive dysfunction. Diabetes Metab Res Rev 30(5): 341-345.

26. Hamed SA (2017) Brain injury with diabetes mellitus: evidence, mechanisms and treatment implications. Expert Rev ClinPharmacol 10(4): 409- 428.

27. Twig G, Gluzman I, Tirosh A, Hertzel C Gerstein, Gal Yaniv, et al. (2014) Cognitive function and the risk for diabetes among young men. Diabetes Care 37(11): 2982-2988.

28. Brands AM, Biessels GJ, de Haan EH, Kappelle LJ, Kessels RP, et al. (2005) The effects of type 1 diabetes on cognitive performance: a meta-analysis. Diabetes Care 28(3): 726-735.

29. Northam EA, Anderson PJ, Jacobs R, Hughes M, Warne GL, et al. (2001) Neuropsychological profiles of children with type 1 diabetes 6 years after disease onset. Diabetes Care 24(9): 1541-1546.

30. McCall AL (2005) Altered glycemia and brain-update and potential relevance to the aging brain. Neurobiology of Aging 26(1): 70-75.

31. Munshi M, Grande L, Hayes M, Ayres D, Suhl E, et al. (2006) Cognitive dysfunction is associated with poor diabetes control in older adults. Diabetes Care 29(8): 1794-1799.

32. Bruce DG, Casey GP, Grange V, Clarnette RC, Almeida OP, et al. (2003) Cognitive impairment, physical disability and depressive symptoms in older diabetic patients: the Fremantle Cognition in Diabetes Study. Diabetes Res ClinPract 61(1): 59-67.

33. Sinclair AJ, Girling AJ, Bayer AJ (2000) Cognitive dysfunction in older subjects with diabetes mellitus: impact on diabetes self management and use of care services. all wales research into elderly (AWARE) study. Diabetes Res Clin Pract 50(3): 203-212.

34. Ott A, Stolk RP, Hofman A, van Harskamp F, Grobbee DE, et al. (1996) Association of diabetes mellitus and dementia: the rotterdam study. Diabetologia 39(11): 1392-1397.

35. Sullivan MG (2006) Glycemic control shown to prevent dementia. $10^{\text {th }}$ International conference on alzheimer's disease and related disorders, Madrid, Spain

36. Reaven GM, Thompson LW, Nahum D, Haskins E (1990) Relationship between hyperglycemia and cognitive function in older NIDDM patients. Diabetes Care 13(1): 16-21. 
37. Sommerfield AJ, Deary IJ, Frier BM (2004) Acute hyperglycemia alters mood state and impairs cognitive performance in people with Type 2 diabetes. Diabetes Care 27(10): 2335-2340.

38. Kumari M, Marmot M (2005) Diabetes and cognitive function in a middle-aged cohort: findings from the Whitehall II study. Neurology 65(10): 1597-1603.

39. Warren RE, Zammitt NN, Deary IJ, Frier BM (2007) The effects of acute hypoglycaemia on memory acquisition and recall and prospective memory in type 1 diabetes. Diabetologia 50(1): 178-185.

40. Jacobson AM, Musen G, Ryan CM, Silvers N, Cleary P, et al. (2007) Longterm effect of diabetes and its treatment on cognitive function. $\mathrm{N}$ Engl J Med, 356(18): 1842-1852.

41. Chabriat H, Sachon C, Levasseur M, Andre Grimaldi, Sabina Pappata (1994) Brain metabolism after recurrent insulin induced hypoglycaemic episodes: a PET study. J NeurolNeurosurg Psychiatry 57: 1360-1365.

42. Perros P, Deary IJ, Sellar RJ, Jonathan JK, Brian M Frier, et al. (1997) Brain abnormalities demonstrated by magnetic resonance imaging in adult IDDM patients with and without a history of recurrent severe hypoglycaemia. Diabetes Care 20 (6): 1013-1018.

43. Kaufman FR, Epport K, Engilman R, Halvorson M (1999) Neurocognitive functioning in children diagnosed with diabetes before age 10 years. J Diabetes Complications 13(1): 31-38.

44. Åsvold BO, Sand T, Hestad K, Marit R Bjørgaas (2010) Cognitive function in Type 1 diabetic adults with early exposed to severe hypoglycaemia, A 16-year follow-up study. Diabetes Care 33(9): 1945-1947.

45. Kodl CT, Seaquist ER (2008) Cognitive dysfunction and diabetes mellitus. Endocr Rev 29(4): 494-511.

46. Whitmer RA, Karter AJ, Yaffe K, Quesenberry CP Jr, Selby JV (2009) Hypoglycemic episodes and risk of dementia in older patients with Type 2 diabetes mellitus. JAMA 301(15): 1565-1572.

47. Punthakee Z, Miller ME, Launer LJ, Williamson JD, Lazar RM, et al (2012) Poor cognitive function and risk of severe hypoglycemia in type 2 diabetes. Post hoc epidemiologic analysis of the ACCORD trial. Diabetes Care 35(4): 787-793.

48. Moran C, Phan TG, Chen J, Blizzard L, Beare R, et al. (2013) Brain atrophy in Type 2 diabetes regional distribution and influence on cognition. Diabetes Care 36(12): 4036-4042.

49. Seaquist ER (2015) The Impact of Diabetes on Cerebral Structure and Function. Psychosom Med 77(6): 616-621.

50. Stiles MC, Seaquist ER (2010) Cerebral structural and functional changes in Type 1 diabetes. Minerva Med 101(2): 105-114.

51. Perantie DC, Wu J, Koller JM, Audrey Lim, Stacie L. Warren, et al. (2007) Regional brain volume differences associated with hyperglycemia and severe hypoglycemia in youth with Type 1 diabetes. Diabetes Care 30(9): 2331-2337.

52. Brownlee M (2001) Biochemistry and Molecular Cell Biology of Diabetic Complications. Nature 414(6865): 813-820.

53. Malone JI, Hanna SK, Liang X (2007) Diabetes increases polyol pathway activity in the brain which is blocked by sorbinil. Diabetes 56(Suppl 1):

54. Brownlee M (2005) The pathobiology of diabetic complications: a unifying mechanism. Diabetes 54(6): 1615-1625.

55. Yan SD, Stern D, Schmidt AM (1997) What's the RAGE? The receptor for advanced glycation end products (RAGE) and the dark side of glucose. Eur J Clin Invest 27(3): 179-181.

56. Girones X, Guimera A, Cruz Sanchez CZ, Ortega A, Sasaki N, et al. (2004) $\mathrm{N}$ epsilon-carboxymethyllysine in brain aging, diabetes mellitus, and Alzheimer's disease. Free Radic Biol Med 36(10): 1241-1247.
57. Ramakrishnan R, Sheeladevi R, Suthanthirarajan N (2004) PKC- $\alpha$ mediated alterations of indoleamine contents in diabetic rat brain. Brain Res Bull 64(2): 189-194.

58. Castellani RJ, Siedlak SL, Fortino AE, Perry G, Ghetti B, Smith MA, et al. (2005) Chitin-like polysaccharides in alzheimer's disease brains. Curr Alzheimer Res 2(4): 419-423.

59. Biessels GJ, Kappelle AC, Bravenboer B, Erkelens DW, Gispen WH, et al. (1994) Cerebral function in diabetes mellitus. Diabetologia 37(7): 643650

60. Tesfaye N, Seaquist ER (2010) Neuroendocrine responses to hypoglycemia. In: Powers AC, Ahima RS, Malden (Eds.), Year in Diabetes and Obesity. Wiley Blackwell, USA, pp. 12-28.

61. Jauch Chara K, Hallschmid M, Gais S, et al. (2007) Hypoglycemia during sleep impairs consolidation of declarative memory in type 1 diabetic and healthy humans. Diabetes Care 30(8): 2040-2045.

62. Siesjo BK, Bengtsson F (1989) Calcium fluxes, calcium antagonists, and calcium-related pathology in brain ischemia, hypoglycemia, and spreading depression: a unifying hypothesis. J Cereb Blood Flow Metab 9(2): 127-140.

63. Wieloch T (1985) Hypoglycemia-induced neuronal damage prevented by an N-methyl-D-aspartate antagonist. Science 230(4726): 681-683.

64. Strachan MWJ (1999) Frequency, causes and risk factors for hypoglycaemia in type 1 diabetes. In: Frier BM, Fisher M (Eds.) Hypoglycemia In Clinical Diabetes. ( $2^{\text {nd }}$ edn), John Wiley and Sons, New York, USA, pp. 49-82.

65. Biessels GJ, Staekenborg S, Brunner E, Brayne C, Scheltens P, et al. (2006) Risk of dementia in diabetes mellitus: a systematic review. Lancet Neurol 5(1): 64-74

66. Frier BM (2011) Cognitive functioning in type 1 diabetes: the diabetes control and complications trial (dcct) revisited. Diabetologia 54(2): 233 236.

67. Van de Ven KCC, Tack CJ, Heerschap A, Marinette van der Graaf, Bastiaan E de Galan, et al. (2013) Patients with type 1 diabetes exhibit altered cerebral metabolism during hypoglycemia. J Clin Invest 123(2): 623629.

68. Jacobson AM, Musen G, Ryan CM (2009) Diabetes control and complications trial/epidemiology of diabetes interventions and complications study research group. N Engl J Med 356(18): 1842-1852.

69. Yaffe K, Blackwell T, Whitmer RA, Krueger K, Barrett Connor E, et al. (2000) Glycosylated hemoglobin level and development of mild cognitive impairment or dementia in older women. J Nutr Health Aging $10(4): 293-295$

70. Janson J, Laedtke T, Parisi JE, O Brien P, Petersen RC, et al. (2004) Increased risk of type 2 diabetes in Alzheimer disease. Diabetes 53(2): 474-481.

71. Stone WS, Cottrill KL, Walker DL, Gold PE (1988) Blood glucose and brain function: interactions with CNS cholinergic systems. Behav Neural Biol 50(3): 325-334.

72. Simpson IA, Chundu KR, Davies Hill T, Honer WG, Davies P, et al. (1994) Decreased concentrations of GLUT1 and GLUT3 glucose transporters in the brains of patients with Alzheimer's disease. Ann Neurol 35(5): 546551.

73. Craft S, Newcomer J, Kanne S, Dagogo Jack S, Cryer P, et al. (1996) Memory improvement following induced hyperinsulinemia in Alzheimer's disease. Neurobiol Aging 17(1): 123-130.

74. Rabera J, Huangb Y, Ashfor JW (2004) ApoE genotype accounts for the vast majority of AD risk and AD pathology. Neurobiology of Aging 25(5): 641-650. 
75. Kota LN, Shankarappa BM, Shivakumar P (2012) Southern India International Journal of Alzheimer's Disease 2012: 4.

76. Miller B, Willett KC, Desilets AR (2011) Rosiglitazone and Pioglitazone for the Treatment of Alzheimer's Disease. Annals of Pharmacotherapy 45(11): 1416-1424.

77. Duckrow RB, Beard DC, Brennan RW (1987) Regional cerebral blood flow decreases during chronic and acute hyperglycemia. Stroke 18: 52 58.

78. Biessels GJ, Kappelle AC, Bravenboer B, Erkelens DW, Gispen WH (1994) Cerebral function in diabetes mellitus. Diabetologia 37(7): 643-650.

79. McCall AL (1992) The impact of diabetes on the CNS. Diabetes 41(5): 557-570.

80. Li PA, Shuaib A, Miyashita H, He QP, Warner DS, et al. (2000) Hyperglycemia enhances extracellular glutamate accumulation in rats subjected to forebrain ischemia. Stroke 31(1): 183-192.

81. Sima AA, Li ZG (2005) The effect of C-peptide on cognitive dysfunction and hippocampal apoptosis in type 1 diabetic rats. Diabetes 54(5): 1497-1505.

82. Galeffi F, Shetty PK, Sadgrove MP, Turner DA (2015) Age-related metabolic fatigue during low glucose conditions in rat hippocampus. Neurobiol Aging 36(2): 982-992.

83. Kodl CT, Seaquist ER (2008) Cognitive dysfunction and diabetes mellitus. Endocr Rev 29(4): 494-511.

84. Areosa Sastre A, Vernooij RW, González Colaço Harmand M, Martínez G (2017) Effect of the treatment of Type 2 diabetes mellitus on the development of cognitive impairment and dementia. Cochrane Database Syst Rev 6: CD003804.

85. Cheng G, Huang C, Deng H, Wang H (2012) Diabetes as a risk factor for dementia and mild cognitive impairment: a meta-analysis of longitudinal studies Intern Med J 42(5): 484-491.

86. Ryan JP, Fine DF, Rosano C (2014) Type 2 diabetes and cognitive impairment: contributions from neuroimaging. J Geriatr Psychiatry Neurol 27(1): 47-55

87. Cui Y, Jiao Y, Chen YC, Kun Wang, Bo Gao, et al. (2014) Altered spontaneous brain activity in type 2 diabetes: a resting-state functional MRI study. Diabetes 63(2): 749-760.

88. Zhang Y, Lu S, Liu C, Huimei Zhang, Xuanhe Zhou, et al. (2016) Altered brain activation and functional connectivity in working memory related networks in patients with type 2 diabetes: An ICA-based analysis. Sci Rep 6: 23767.

89. Van Bussel FCG, Backes WH, Hofman PAM, van Oostenbrugge RJ, van Boxtel MPJ, et al. (2017) Cerebral pathology and cognition in diabetes: the merits of multiparametric neuroimaging. Front Neurosci 11: 188.

90. vanBussel FC, Backes WH, Hofman PA, Puts NA, Edden RA, et al. (2016) Increased GABA concentrations in type 2 diabetes mellitus are related to lower cognitive functioning. Medicine (Baltimore) 95(36): e4803.

91. Wardlaw J M, Smith EE, Biessels GJ, Cordonnier C, Fazekas F, et al. (2013) Neuroimaging standards for research into small vessel disease and its contribution to ageing and neurodegeneration. Lancet Neurol 12(8): 822-838.

92. Jansen JF, Van Bussel FC, Van De Haar HJ, Matthias JP van Osch, Paul AM Hofman, et al. (2016) Cerebral blood flow, blood supply, and cognition in Type 2 Diabetes Mellitus. Sci Rep 6: 10.

93. van Bussel FC, Backes WH, Hofman PA, van Oostenbrugge RJ, Kessels $A G$, et al. (2015) On the interplay of microvasculature, parenchyma, and memory in type 2 diabetes. Diabetes Care 38(5): 876-882.

94. Wardlaw JM, Smith EE, Biessels GJ, Cordonnier C, Fazekas F, et al. (2013)
Neuroimaging standards for research into small vessel disease and its contribution to ageing and neurodegeneration. Lancet Neurol 12(8): 822-838.

95. Schneider JA, Wilson RS, Cochran EJ, Bienias JL, Arnold SE, et al. (2003) Relation of cerebral infarctions to dementia and cognitive function in older persons. Neurology 60(7): 1082-1088.

96. Kawamura T, Umemura T, Hotta N (2012) Cognitive impairment in diabetic patients: Can diabetic control prevent cognitive decline? J Diabetes Investig 3(5): 413-423.

97. Kodl CT, Seaquist ER (2008) Cognitive dysfunction and diabetes mellitus. Endocr Rev 29(4): 494-511.

98. Munshi M, Grande L, Hayes M, Ayres D, Suhl E, et al. (2006) Cognitive dysfunction is associated with poor diabetes control in older adults. Diabetes Care 29(8): 1794-1799.

99. Bruce DG, Davis WA, Casey GP, Starkstein SE, Clarnette RM, et al. (2008) Predictors of cognitive impairment and dementia in older people with diabetes. Diabetologia 51(2): 241-248.

100. Cukierman Yaffe T, Gerstein HC, Williamson JD, Lazar RM, Lovato L, et al. (2009) Relationship between baseline glycemic control and cognitive function in individuals with type 2 diabetes and other cardiovascular risk factors. The Action to Control Cardiovascular Risk in Diabetes-Memory in Diabetes (ACCORD-MIND) trial. Diabetes Care 32(2): 221-226.

101. Yaffe K, Blackwell T, Whitmer RA, et al. (2006) Glycosylated hemoglobin level and development of mild cognitive impairment or dementia in older women. J Nutr Health Aging 10(4): 293-295.

102. (2007) The Diabetes Control and Complication Trial/Epidemiology of Diabetes Intervention and Complications (DCCT/EDIC) Study Research Group. Long-term effect of diabetes and its treatment on cognitive function. N Engl J Med 356: 1842-1852.

103. Euser SM, Sattar N, Wittman CM, Bollen EL, Sijbrands EJ, et al. (2010) A prospective analysis of elevated fasting glucose levels and cognitive function in older people. Results from PROSPER and the Rotterdam study. Diabetes 59(7): 1601-1607.

104. Kwok CF, Ho LT (2012) Severe hypoglycemia predicts major adverse outcomes in diabetic patients undergoing glycemic control regimes. J Diabetes Invest 3(1): 34-35.

105. Rizzo MR, Marfella R, Barbieri M, Boccardi V, Vestini F, et al. (2010) Relationships between daily acute glucose fluctuations and cognitive performance among aged Type 2 diabetic patients. Diabetes Care 33(10): 2169-2174.

106. Ohara T, Doi Y, Ninomiya T, Hirakawa Y, Hata J, et al. (2011) Glucose tolerance status and risk of dementia in the community. The Hisayama Study. Neurology 77(12): 1126-1134

107. Raffaitin CR, Féart C, Le Goff M, Amieva H, Helmer C, et al (2011) Metabolic syndrome and cognitive decline in French elders: the threecity study. Neurology 76(6): 518-525

108. Whitmer RA (2007) Type 2 diabetes and risk of cognitive impairment and dementia. Curr Neurol Neurosci Rep 7(5): 373-380.

109. Ryan CM, Fried MI, Rood JA, Cobitz AR, Waterhouse BR, et al. (2006) Improving metabolic control leads to better working memory in adults with Type 2 diabetes. Diabetes Care 29(2): 345-351.

110. Wu JH, Haan MN, Liang J, Ghosh D, Gonzalez HM, et al. (2003) Impact of antidiabetic medications on physical and cognitive functioning of older Mexican Americans with diabetes mellitus: a population-based cohort study. Ann Epidemol 13(5): 369-376.

111. Sato T, Hanyu H, Hirao K, Kanetaka H, Sakurai H, et al. (2011) Efficacy of PPAR- $\gamma$ agonist pioglitazone in mild Alzheimer disease. Neurobiol Aging 32(9): 1626-1633. 
112. Shemesh E, Rudich A, Harman Boehm I, Cukierman Yaffe T (2012) Effect of intranasal insulin on cognitive function-A systematic review. Clin Endocrinol Metab 97(2): 366-376.

113. Bomfim TR, Forny Germano L, Sathler LB, Brito Moreira J, Houzel JC, et al. (2012) An anti-diabetes agent protects the mouse brain from defective insulin signaling caused by Alzheimer's disease- associated $\mathrm{A} \beta$ oligomers. J Clin Invest 122(4): 1339-1353.

114. Logroscino G, Kang JH, Grodstein F (2004) Prospective study of type 2diabetes and cognitive decline in women aged 70-81 years. BM] 328(7439): 5480 .

115. Mogi N, Umegaki H, Hattori A, Maeda N, Miura H, et al. (2004) Cognitive function in Japanese elderly with type 2 diabetes mellitus. J Diabetes Complications 18(1): 42-46.

116. Mergenthaler P, Lindauer U, Dienel GA (2013) Sugar for the brain: the role of glucose in physiological and pathological brain function. Trends Neurosci 36(10): 587-597.

117. Harris JJ, Jolivet R, Attwell D (2012) Synaptic energy use and supply. Neuron 75(5): 762-777.

118. Harris JJ, Attwell D (2012) The energetics of CNS white matter. Neurosci 32(1): 356-371.

119. Craft S (2005) Insulin resistance syndrome and Alzheimer's disease: age- and obesity-related on memory, amyloid, and inflammation. Neurobiol Aging 26 Suppl 1: S65-S69.

120. Woods SC, Seeley RJ, Baskin DG, Schwartz MW (2003) Insulin and the blood-brain barrier. Curr Pharm Des, 9: 795-800

121. Craft S, Watson GS (2004) Insulin and neurodegenerative disease: shared and specific mechanisms. Lancet Neurol 3(3): 169-178.

122. Young SE, Mainous AG, Carnemolla M (2006) Hyperinsulinemia and cognitive decline in a middle-aged cohort. Diabetes Care 29(12): 2688 2693

123. Matsuzaki T, Sasaki K, Tanizaki Y, Hata J, Fujimi K, et al. (2010) Insulin resistance is associated with the pathology of Alzheimer disease. The Hisayama Study: Neurology 75(9): 764-770.

124. Rönnenmaa E, Zethelius B, Sundelöf J, Sundström J, Degerman Gunnarsson M, et al. (2009) Glucose metabolism and the risk of Alzheimer's disease and dementia: a population-based 12 years follow-up study in 71-years-old men. Diabetologia 52(8): 1504-1510.

125. Kroemer G, Marino G, Levine B (2010) Autophagy and the integrated stress response. Mol Cell 40(2): 280-293.

126. Gimenez Cassina A, Lim F, Cerrato T, Cerrato T, Palomo GM, et al (2009) Mitochondrial hexokinase II promotes neuronal survival and acts downstream of glycogen synthase kinase-3. J Biol Chem 284(5): 3001-3011.

127. Kapogiannis D, Mattson MP (2011) Disrupted energy metabolism and neuronal circuit dysfunction in cognitive impairment and Alzheimer's disease. Lancet Neurol 10(2): 187-198.

128. Scheen AJ (2010) Central nervous system: a conductor orchestrating metabolic regulations harmed by both hyperglycaemia and hypoglycaemia. Diabetes Meta 36(Suppl 3): S31-S38

129. Biessels GJ, Reijmer YD (2014) Brain changes underlying cognitive dysfunction in diabetes: what can we learn from MRI? Diabetes 63(7): 2244-2252.

130. Van Bussel FCG, Backes WH, Hofman PAM, Robert J van Oostenbrugge, Martin PJ van Boxtel, et al. (2017) Cerebral Pathology and Cognition in Diabetes: The merits of multiparametric neuroimaging. Front Neurosci 11: 188

131. Nikhra V (2017) The aging brain: recent research and concepts. Gerontol \& Geritric Stud 1(3): 1-11.

132. Xu W, Caracciolo B, Wang HX, Winblad B, Bäckman L, et al. (2010) Accelerated progression from mild cognitive impairment to dementia in people with diabetes. Diabetes 59(11): 2928-2935.

133. Ruis C, Biessels GJ, Gorter KJ, van den Donk M, Kappelle LJ, et al. (2009) Cognition in the early stage of type 2 diabetes. Diabetes Care 32(7): 1261-1265.

134. Wennberg AMV, Hagen CE, Gottesman RF, Zipunnikov V, Kaufmann CN et al. (2017) Longitudinal association between diabetes and cognitive decline: the national health and aging trends study. Arch Gerontol Geriatr 72: 39-44

135. Barnes D, Yaffe K (2011) The projected effect of risk factor reduction on Alzheimer's disease prevalence. Lancet Neurol 10(9): 819-828.

136. Alonso A, Mosley TH Jr, Gottesman RF (2009) Risk of dementia hospitalization associated with cardiovascular risk factors in midlife and older age: the atherosclerosis risk in communities (ARIC) study. J Neurol Neurosurg Psychiatry 80(11): 1194-1201.

137. Barbieri M, Boccardi V, Paolisso G (2015) Chapter-Cognitive Decline and Diabetes: a focus on linking mechanisms. In: Colin Martin, Victor Preedy (Eds.), Diet and nutrition in dementia and cognitive decline, Academic Press, USA, pp. 393-402.

138. Spindler SR (2010) Chapter-Biological Effects of Calorie Restriction: Implications for modification of human aging. In: Fahy GM (Ed.), The future of aging: pathways to human life extension, Springer, New York, USA, pp. 367-438.

139. Feinkohl I, Price JF, Strachan MWJ, Frier BM (2015) The impact of diabetes on cognitive decline: potential vascular, metabolic, and psychosocial risk factors. Alzheimers Res Ther 7(1): 46.

140. Rawlings AM, Sharrett AR, Mosley TH, Ballew SH, Deal JA, et al. (2017) Glucose peaks and the risk of dementia and 20-year cognitive decline. Diabetes Care 40(7): 879-886.
Creative Commons Attribution 4.0 International License

For possible submissions Click Here

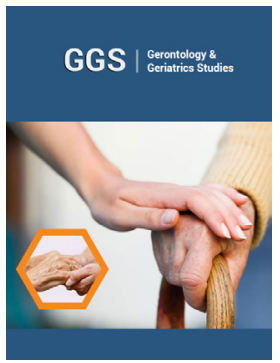

Gerontology \& Geriatrics Studies

\section{Benefits of Publishing with us}

- High-level peer review and editorial services

- Freely accessible online immediately upon publication

- Authors retain the copyright to their work

- Licensing it under a Creative Commons license

- Visibility through different online platforms 